\title{
Male Disadvantage in Oxidative Stress-Associated Complications of Prematurity: A Systematic Review, Meta-Analysis and Meta-Regression
}

\author{
Elke van Westering-Kroon ${ }^{1}$, Maurice J Huizing ${ }^{1}$, Eduardo Villamor-Martínez ${ }^{1,2}$ and Eduardo Villamor ${ }^{1, *}$ (D) \\ 1 Department of Pediatrics, Maastricht University Medical Center (MUMC+), School for Oncology and \\ Developmental Biology (GROW), 6229HA Maastricht, The Netherlands; elke.kroon@mumc.nl (E.v.W.-K.); \\ m.huizing@mumc.nl (M.J.H.); e.villamorm@gmail.com (E.V.-M.) \\ 2 Statistics Netherlands, 6412HX Heerlen, The Netherlands \\ * Correspondence: e.villamor@mumc.nl
}

check for updates

Citation: van Westering-Kroon, E.; Huizing, M.J.; Villamor-Martínez, E.; Villamor, E. Male Disadvantage in Oxidative Stress-Associated Complications of Prematurity: A Systematic Review, Meta-Analysis and Meta-Regression. Antioxidants 2021, 10, 1490. https://doi.org/ 10.3390/antiox10091490

Academic Editors: Julia Kuligowski and Máximo Vento

Received: 30 August 2021

Accepted: 14 September 2021

Published: 18 September 2021

Publisher's Note: MDPI stays neutral with regard to jurisdictional claims in published maps and institutional affiliations.

Copyright: (C) 2021 by the authors Licensee MDPI, Basel, Switzerland. This article is an open access article distributed under the terms and conditions of the Creative Commons Attribution (CC BY) license (https:// creativecommons.org/licenses/by/ $4.0 /)$

\begin{abstract}
A widely accepted concept is that boys are more susceptible than girls to oxidative stressrelated complications of prematurity, including bronchopulmonary dysplasia (BPD), retinopathy of prematurity (ROP), necrotizing enterocolitis (NEC), intraventricular hemorrhage (IVH), and periventricular leukomalacia (PVL). We aimed to quantify the effect size of this male disadvantage by performing a systematic review and meta-analysis of cohort studies exploring the association between sex and complications of prematurity. Risk ratios (RRs) and 95\% CIs were calculated by a random-effects model. Of 1365 potentially relevant studies, 41 met the inclusion criteria (625,680 infants). Male sex was associated with decreased risk of hypertensive disorders of pregnancy, fetal distress, and C-section, but increased risk of low Apgar score, intubation at birth, respiratory distress, surfactant use, pneumothorax, postnatal steroids, late onset sepsis, any NEC, NEC > stage 1 (RR 1.12, CI 1.06-1.18), any IVH, severe IVH (RR 1.28, CI 1.22-1.34), severe IVH or PVL, any BPD, moderate/severe BPD (RR 1.23, CI 1.18-1.27), severe ROP (RR 1.14, CI 1.07-1.22), and mortality (RR 1.23, CI 1.16-1.30). In conclusion, preterm boys have higher clinical instability and greater need for invasive interventions than preterm girls. This leads to a male disadvantage in mortality and short-term complications of prematurity.
\end{abstract}

Keywords: preterm birth; oxidative stress; sex differences; male disadvantage; female advantage; bronchopulmonary dysplasia; retinopathy of prematurity; necrotizing enterocolitis; intraventricular hemorrhage; periventricular leukomalacia; mortality

\section{Introduction}

Preterm birth is defined as birth before 37 completed weeks of gestational age (GA) and is further subdivided in extremely (GA $<28$ weeks), very (GA 28 to $<32$ weeks), moderate (GA 32 to $<34$ weeks), and late (GA 34 to $<37$ weeks) preterm birth. Prematurity, particularly in the in the lowest ranges of GA, is a leading cause of infant mortality, as well as long-term morbidity [1].

Two widely accepted concepts in neonatal medicine are the so-called "male disadvantage" and "oxygen radical disease in neonatology". The first concept is supported by a large body of evidence showing that boys are more susceptible than girls to adverse outcomes of prematurity, including bronchopulmonary dysplasia (BPD), retinopathy of prematurity (ROP), necrotizing enterocolitis (NEC), intraventricular hemorrhage (IVH), periventricular leukomalacia (PVL), chronic neurodevelopmental and cognitive impairment, and death [2-7].

The term "oxygen radical disease in neonatology" was coined by Saugstad in the 1980s when he hypothesized that complications of prematurity, such as BPD, ROP, NEC, IVH, or PVL, are different facets of one disease sharing a basic pathogenetic mechanism: increased 
oxidative stress and reduced endogenous antioxidant defenses [8,9]. Interestingly, preterm girls have higher antioxidant enzyme activity than preterm boys and it has been suggested that these differences may play a key role in the male disadvantage of prematurity [10-12].

Although the notion of male disadvantage of prematurity is more than five decades old, only sex-associated differences in mortality have been systematically reviewed [13]. Our current aim is to conduct a systematic review and meta-analysis on male-female differences in risk of developing oxidative stress-associated complications of prematurity. In addition to outcomes such as BPD, ROP, NEC, IVH, or PVL, we also analyzed potential male-female differences in obstetrical characteristics and clinical conditions in the first weeks of postnatal life. Finally, since it has been suggested that the male disadvantage of prematurity has undergone changes in the last few years [14], we investigated by metaregression the influence of time and other variables on the association between infant sex and complications of prematurity.

\section{Materials and Methods}

The study was performed and reported according to the preferred reporting items for systematic reviews and meta-analyses (PRISMA) and meta-analysis of observational studies in epidemiology (MOOSE) guidelines [15]. Review protocol was registered in the PROSPERO international register of systematic reviews (ID = CRD42018095509). The research question was "Do preterm boys have a higher risk of developing short-term complications of prematurity than preterm girls?"

\subsection{Sources and Search Strategy}

A comprehensive literature search was undertaken using the PubMed and EMBASE databases. The search strategy is detailed in Table S1. No language limit was applied. The literature search was updated up to February 2021. Narrative reviews, systematic reviews, case reports, letters, editorials, and commentaries were excluded, but read to identify potential additional studies. Additional strategies to identify studies included manual review of reference lists from key articles that fulfilled our eligibility criteria, use of "related articles" feature in PubMed, and use of the "cited by" tool in Web of Science and Google scholar.

\subsection{Study Selection}

Studies were included if they had a prospective or retrospective cohort design, examined preterm $(\mathrm{GA}<37$ weeks) infants, and reported primary data that could be used to measure the association between infant sex and short-term complications of prematurity. We only selected studies in which infant sex was the independent variable and the perinatal characteristics and outcomes were the dependent variables. Studies that exclusively included late preterm infants ( $\mathrm{GA} \geq 34$ weeks), or combined preterm and term infants were excluded. To identify relevant studies, two reviewers (E.V., E.V.-M.) independently screened the results of the searches and applied inclusion criteria using a structured form. Discrepancies were resolved through discussion or consultation with a third reviewer (M.J.H.).

\subsection{Data Extraction and Quality Assessment}

Two reviewers (E.V., E.V.-M.) extracted data from relevant studies using a predetermined data extraction form, and two reviewers (E.W.-K., M.J.H.) checked data extraction for accuracy and completeness. Discrepancies were resolved by consulting the primary report. Data extracted from each study included citation information, language of publication, study design, location and frame time, patient characteristics, and results (including raw numbers or summary statistics when raw numbers were not available). Data were extracted for all obstetric and perinatal variables as well as clinical conditions and outcomes reported in each study. 
Methodological quality was assessed using the Newcastle-Ottawa Scale (NOS) for cohort studies [15]. This scale assigns a maximum of 9 points (4 for selection, 2 for comparability, and 3 for outcome). NOS scores $\geq 7$ were considered high-quality studies (low risk of bias), and scores of 5 to 6 denoted moderate quality (moderate risk of bias) [15].

\subsection{Statistical Analysis}

Meta-analysis was performed when at least three studies were identified that reported on the same variable or outcome measure. Studies were combined and analyzed using comprehensive meta-analysis V3.0 software (Biostat Inc., Englewood, NJ, USA). Due to anticipated heterogeneity, summary statistics were calculated with a random-effects model. This model accounts for variability between studies as well as within studies. For dichotomous outcomes, the risk ratio (RR) with $95 \%$ confidence interval (CI) was calculated. For continuous outcomes (example: GA), the mean difference (MD) with 95\% CI was calculated. Statistical heterogeneity was assessed by Cochran's $Q$ statistic and by the $I^{2}$ statistic. Potential sources of heterogeneity were assessed through subgroup analysis and/or random effects (method of moments) univariate meta-regression analysis as previously described $[16,17]$. For both categorical and continuous covariates, the $\mathrm{R}^{2}$ analog, defined as the total between-study variance explained by the moderator, was calculated based on the meta-regression matrix. Predefined sources of heterogeneity included the following characteristics of cohorts: mean or median GA, median year of birth, and geographical location (continent). We used the Egger's regression test and funnel plots to assess publication bias. Subgroup analyses, meta-regression, and publication bias assessment were performed only for the main outcomes (BPD, IVH, PVL, ROP, NEC, and mortality) and when there were at least ten studies in the meta-analysis. A probability value of less than 0.05 ( 0.10 for heterogeneity) was considered statistically significant.

\section{Results}

\subsection{Description of Studies and Quality Assessment}

The flow diagram of the search process is shown in Figure S1. Of 1365 potentially relevant studies, 41 (including 625,680 infants, 319,470 males) were included [2-5,14,18-53]. Their characteristics are summarized in Table S2. The percentage of males in the cohorts ranged from $41.2 \%$ [32] to $66.2 \%$ [20] with a pooled percentage of $52.2 \%$ (95\% CI 51.4 to 53.0). Four studies included exclusively twin infants $[24,35,44,51]$ and two studies included exclusively singleton infants $[43,49]$. The quality score of each study according to the Newcastle-Ottawa Scale is depicted in Table S2. All studies received at least seven points, indicating a low risk of bias.

\subsubsection{Meta-Analysis}

The following variables were reported in more than two studies and were therefore included in the meta-analysis: chorioamnionitis, hypertensive disorders of pregnancy, maternal diabetes, prenatal care, premature rupture of membranes, prolonged rupture of membranes, antepartum hemorrhage, antenatal corticosteroids, fetal distress, cesareansection, birth in a non-tertiary hospital (outborn), $5^{\prime}$ Apgar score $<3,5^{\prime}$ Apgar score $<7$, intubation at birth, resuscitation at birth, birth weight (BW) below the 10th percentile, BW below the 3rd percentile or $-2 \mathrm{SD}$, early onset $(<72 \mathrm{~h})$ sepsis, late onset $(>72 \mathrm{~h})$ sepsis, undefined onset sepsis, hypotension, patent ductus arteriosus (PDA), respiratory distress syndrome (RDS), administration of surfactant, mechanical ventilation, pneumothorax, postnatal steroids, any BPD (defined as oxygen requirement on postnatal day 28), moderate/severe BPD (defined as oxygen requirement at the postmenstrual age of 36 weeks), any IVH (grade 1-4), severe IVH (grade 3-4), PVL, severe IVH or PVL, any ROP, severe ROP (stage $\geq 3$ or requiring treatment), any NEC, NEC $\geq$ Stage II, and mortality before discharge.

The meta-analyses on obstetric and perinatal characteristics are summarized in Figure 1 and Table 1. The meta-analyses on clinical characteristics and outcomes are summa- 
rized in Figure 2 and Table 2. The individual meta-analyses for each outcome (BPD, IVH, PVL, ROP, NEC, and mortality) are shown in Figures S2-S12. Male sex was associated with a decreased risk of hypertensive disorders of pregnancy, fetal distress, and cesarean-section, but an increased risk of birth in a non-tertiary hospital, $5^{\prime}$ Apgar score $<3$, intubation at birth, respiratory distress syndrome, surfactant use, pneumothorax, postnatal steroids, late onset sepsis, any BPD (Figures 2 and S2), moderate/severe BPD (Figures 2 and S3), any IVH (Figures 2 and S4), severe IVH (Figures 2 and S5), severe IVH or PVL (Figures 2 and S7), severe ROP (Figures 2 and S9), any NEC (Figures 2 and S10), NEC $\geq$ stage II (Figures 2 and S11), and mortality (Figures 2 and S12). With regard to the continuous variables, BW was significantly higher in boys than in girls (Table 1). In contrast, no differences were found by infant sex in either GA or maternal age (Table 1).

Meta-analysis

Chorioamnionitis

Hypertensive disorders of pregnancy

Maternal diabetes

Smoking during pregnancy

Prenatal care

Premature rupture of membranes

Prolonged rupture of membranes

Antepartum hemorrhage

Antenatal corticosteroids

Cesarean-section

Outborn

5' Apgar <3

5' Apgar $<7$

Intubation at birth

Resuscitation at birth

Birth weight $<$ P10

Birth weight $<$ P3 or $-2 S D$
Risk ratio and $95 \% \mathrm{Cl}$

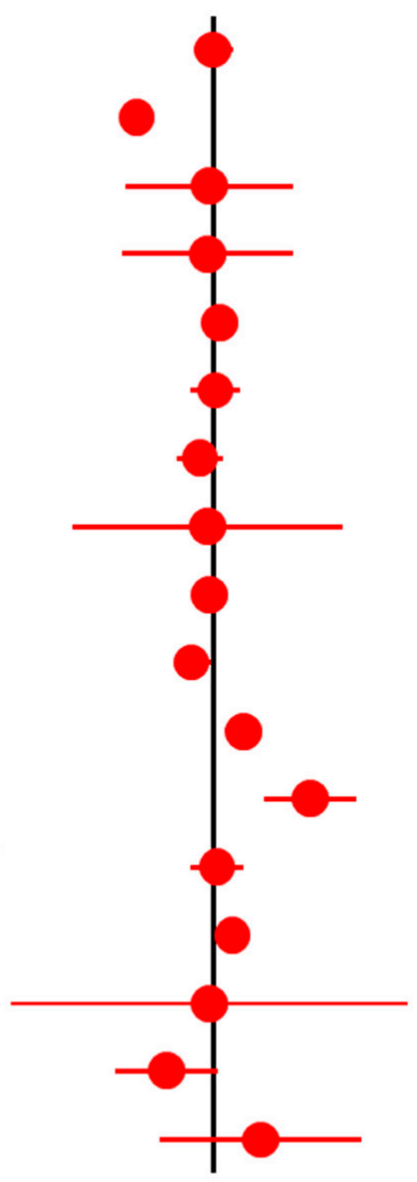

6

15

7

3

5

6

5

3

21

21

9

3

3

5

3

18

3

0.5

1

$\begin{array}{cc}\text { Lower risk } & \text { Higher risk } \\ \text { in males } & \text { in males }\end{array}$

Figure 1. Summary of meta-analyses on the association between obstetric and perinatal characteristics of preterm infants and male sex. CI: confidence interval; K: number of studies; P3: 3rd percentile; P10: 10th percentile; SD: standard deviation. 
Table 1. Meta-analyses on the association between obstetric and perinatal characteristics of preterm infants and male sex.

\begin{tabular}{|c|c|c|c|c|c|c|c|}
\hline \multirow{2}{*}{ Meta-Analysis } & \multirow{2}{*}{$\mathbf{K}$} & \multirow{2}{*}{$\mathbf{R R}$} & \multicolumn{2}{|c|}{$95 \% \mathrm{CI}$} & \multirow{2}{*}{$p$} & \multicolumn{2}{|c|}{ Heterogeneity } \\
\hline & & & Lower Limit & Upper Limit & & $I^{2}(\%)$ & $p$ \\
\hline Chorioamnionitis & 6 & 1.001 & 0.953 & 1.052 & 0.969 & 67.3 & 0.009 \\
\hline $\begin{array}{l}\text { Hypertensive disorders of } \\
\text { pregnancy }\end{array}$ & 15 & 0.829 & 0.803 & 0.856 & $<0.001$ & 22.9 & 0.200 \\
\hline Maternal diabetes & 7 & 0.991 & 0.808 & 1.214 & 0.927 & 65.9 & 0.007 \\
\hline Smoking during pregnancy & 3 & 0.987 & 0.800 & 1.218 & 0.901 & 3.9 & $<0.001$ \\
\hline Prenatal care & 5 & 1.017 & 0.982 & 1.053 & 0.352 & 96.2 & 0.353 \\
\hline $\begin{array}{l}\text { Premature rupture of } \\
\text { membranes }\end{array}$ & 6 & 1.006 & 0.947 & 1.068 & 0.852 & 62.8 & 0.020 \\
\hline $\begin{array}{c}\text { Prolonged rupture of } \\
\text { membranes }\end{array}$ & 5 & 0.968 & 0.914 & 1.026 & 0.275 & 0.0 & 0.972 \\
\hline Antepartum hemorrhage & 3 & 0.986 & 0.708 & 1.374 & 0.936 & 96.9 & $<0.001$ \\
\hline Antenatal corticosteroids & 21 & 0.992 & 0.982 & 1.003 & 0.143 & 44.9 & 0.012 \\
\hline Fetal distress & 3 & 0.784 & 0.678 & 0.907 & 0.001 & 0.0 & 0.741 \\
\hline Cesarean-section & 21 & 0.980 & 0.966 & 0.995 & 0.008 & 51.5 & 0.003 \\
\hline Outborn & 9 & 1.077 & 1.027 & 1.128 & 0.002 & 0.0 & 0.682 \\
\hline Apgar $5^{\prime}<3$ & 3 & 1.269 & 1.132 & 1.422 & $<0.001$ & 0.0 & 0.726 \\
\hline Apgar $5^{\prime}<7$ & 3 & 1.010 & 0.946 & 1.077 & 0.772 & 85.2 & 0.001 \\
\hline Intubation at birth & 5 & 1.038 & 1.006 & 1.071 & 0.019 & 66.4 & 0.018 \\
\hline Resuscitation at birth & 3 & 0.990 & 0.609 & 1.609 & 0.968 & 93.2 & $<0.001$ \\
\hline Birth weight $<$ P10 & 18 & 0.892 & 0.785 & 1.014 & 0.080 & 80.9 & $<0.001$ \\
\hline Birth weight $<\mathrm{P} 3$ & 3 & 1.123 & 0.877 & 1.438 & 0.358 & 51.5 & 0.127 \\
\hline Continuous variables & & MD & & & & & \\
\hline Gestational age (weeks) & 24 & -0.10 & -0.21 & 0.01 & 0.076 & 87.0 & $<0.001$ \\
\hline Birth weight (g) & 24 & 47.8 & 34.1 & 61.5 & $<0.001$ & 91.5 & $<0.001$ \\
\hline Maternal age (years) & 10 & 0.0 & -0.5 & 0.5 & 0.999 & 92.5 & $<0.001$ \\
\hline
\end{tabular}

Random effects analysis. Risk ratio (RR) $>1$ indicates association of male sex with increased risk of the variable and RR $<1$ indicates association of male sex with decreased risk of the variable. K: number of studies, MD: difference of means.

Neither visual inspection of funnel plots (Figure S13) nor Egger's test suggested publication or selection bias for any of the eligible meta-analyses (i.e., with at least ten studies).

\subsubsection{Subgroup Analysis and Meta-Regression}

Subgroup analysis based on the geographic location (continent) of the studies showed no significant differences for any of the outcomes analyzed, with only the exception of PVL (Table S2). The effect size of the association between male sex and PVL was significantly lower (meta-regression $p=0.048, \mathrm{R}^{2}$-analog $=0.5$ ) in the cohorts from America when compared with Asian and European cohorts (Table S3).

Meta-regression showed that the effect size of the association between male sex and mortality significantly decreased as the median year of the cohort increased (Figure 3A). In contrast, the association between male sex and the other outcomes did not correlate with the median year of birth of the cohort (Table S4). Meta-regression also showed that the effect size of the association between male sex and mortality significantly increased as the mean/median gestational age of the cohort increased (Figure 3B). The association between sex and the other outcomes did not correlate with the mean/median gestational age of the cohort (Table S4). 
Meta-analysis

Early onset sepsis

Late onset sepsis

Undefined onset sepsis

Hypotension

PDA

RDS

Surfactant

Mechanical ventilation

Pneumothorax

Postnatal steroids

Any BPD

Moderate/severe BPD

Any IVH

Severe IVH

PVL

Severe IVH/PVL

Any ROP

Severe ROP

Any NEC

NEC stage $\geq$ II

Mortality
Risk ratio and $95 \% \mathrm{Cl} \quad \mathrm{K}$

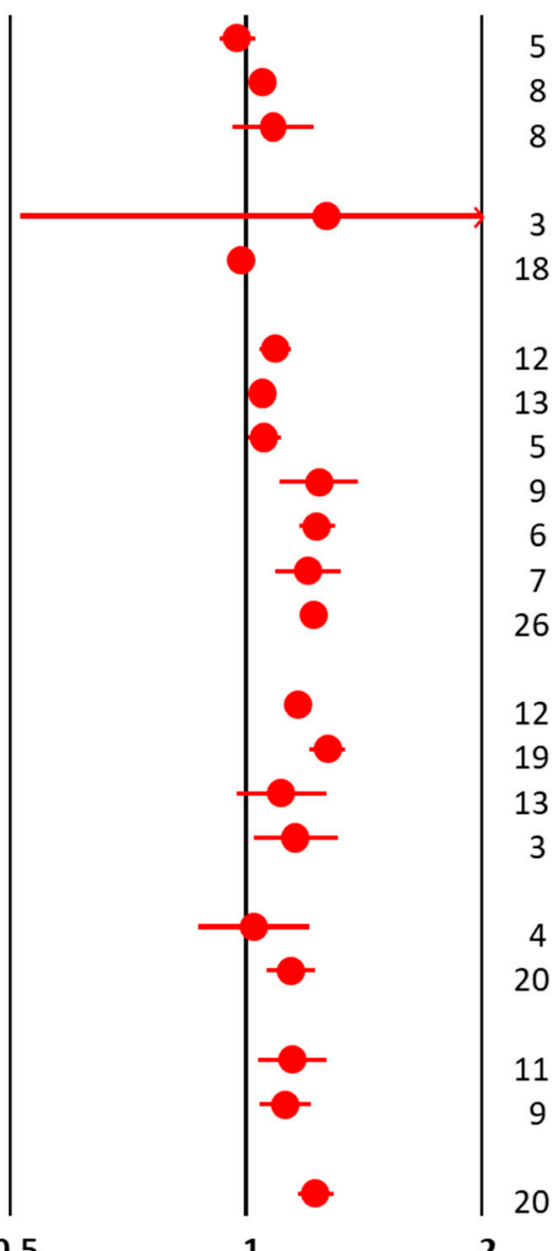

2
Lower risk
Higher risk
in males
in males

Figure 2. Summary of meta-analyses on the association between clinical characteristics and outcomes of preterm infants and male sex. BPD: bronchopulmonary dysplasia; CI: confidence interval; IVH: intraventricular hemorrhage; K: number of studies; NEC: necrotizing enterocolitis; PDA: patent ductus arteriosus; PVL: periventricular leukomalacia; ROP: retinopathy of prematurity.

Table 2. Meta-analyses on the association between clinical characteristics and outcomes of preterm infants and male sex.

\begin{tabular}{|c|c|c|c|c|c|c|c|}
\hline \multirow[b]{2}{*}{ Meta-Analysis } & \multirow[b]{2}{*}{$\mathbf{K}$} & \multirow[b]{2}{*}{$\mathbf{R R}$} & \multicolumn{2}{|c|}{$95 \% \mathrm{CI}$} & \multirow[b]{2}{*}{$p$} & \multicolumn{2}{|c|}{ Heterogeneity } \\
\hline & & & $\begin{array}{l}\text { Lower } \\
\text { Limit }\end{array}$ & $\begin{array}{l}\text { Upper } \\
\text { Limit }\end{array}$ & & $I^{2}(\%)$ & $p$ \\
\hline Early onset sepsis & 5 & 0.975 & 0.924 & 1.030 & 0.371 & 0.0 & 0.459 \\
\hline Late onset sepsis & 8 & 1.051 & 1.026 & 1.077 & $<0.001$ & 17.0 & 0.296 \\
\hline Undefined onset sepsis & 8 & 1.083 & 0.962 & 1.218 & 0.186 & 20.6 & 0.266 \\
\hline Hypotension & 3 & 1.270 & 0.514 & 3.140 & 0.605 & 72.7 & 0.026 \\
\hline PDA & 18 & 0.985 & 0.958 & 1.012 & 0.262 & 52.5 & 0.004 \\
\hline RDS & 12 & 1.090 & 1.042 & 1.140 & $<0.001$ & 96.1 & $<0.001$ \\
\hline Surfactant & 13 & 1.031 & 1.026 & 1.036 & $<0.001$ & 41.4 & 0.059 \\
\hline Mechanical ventilation & 5 & 1.054 & 1.003 & 1.108 & 0.038 & 54.7 & 0.066 \\
\hline
\end{tabular}


Table 2. Cont.

\begin{tabular}{ccccccccc}
\hline Pneumothorax & 9 & 1.240 & 1.104 & 1.393 & $<0.001$ & 42.2 & 0.086 \\
\hline Postnatal steroids & 6 & 1.234 & 1.169 & 1.302 & $<0.001$ & 37.6 & 0.433 \\
\hline Any BPD & 7 & 1.200 & 1.091 & 1.319 & $<0.001$ & 66.0 & 0.004 \\
\hline Moderate/severe BPD & 26 & 1.219 & 1.176 & 1.264 & $<0.001$ & 71.4 & $<0.001$ \\
\hline Any IVH & 12 & 1.166 & 1.139 & 1.193 & $<0.001$ & 0.0 & 0.680 \\
\hline Severe IVH & 19 & 1.271 & 1.207 & 1.338 & $<0.001$ & 40.5 & 0.035 \\
\hline PVL & 13 & 1.110 & 0.971 & 1.269 & 0.128 & 77.3 & $<0.001$ \\
\hline Severe IVH/PVL & 3 & 1.158 & 1.023 & 1.310 & 0.020 & 80.8 & 0.005 \\
\hline Any ROP & 4 & 1.025 & 0.870 & 1.207 & 0.767 & 66.3 & 0.031 \\
\hline Severe ROP & 20 & 1.143 & 1.065 & 1.226 & $<0.001$ & 79.2 & $<0.001$ \\
\hline Any NEC & 11 & 1.145 & 1.036 & 1.266 & 0.008 & 60.1 & 0.003 \\
\hline NEC stage $\geq$ II & 9 & 1.122 & 1.039 & 1.211 & 0.003 & 32.9 & 0.155 \\
\hline Mortality & 20 & 1.227 & 1.163 & 1.294 & $<0.001$ & 83.7 & $<0.001$ \\
\hline Ran
\end{tabular}

Random effects analysis. Risk ratio (RR) $>1$ indicates association of male sex with increased risk of the outcome and RR $<1$ indicates association of male sex with decreased risk of the outcome. K: number of studies.

A

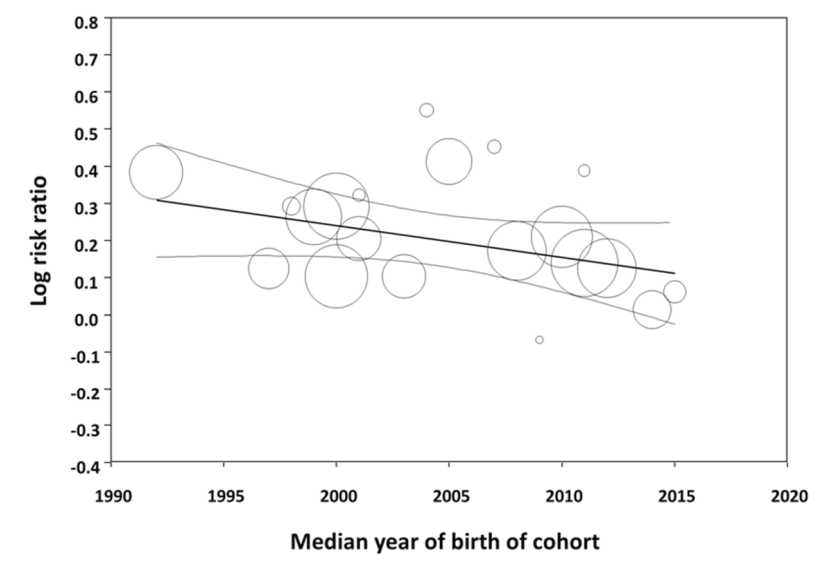

B

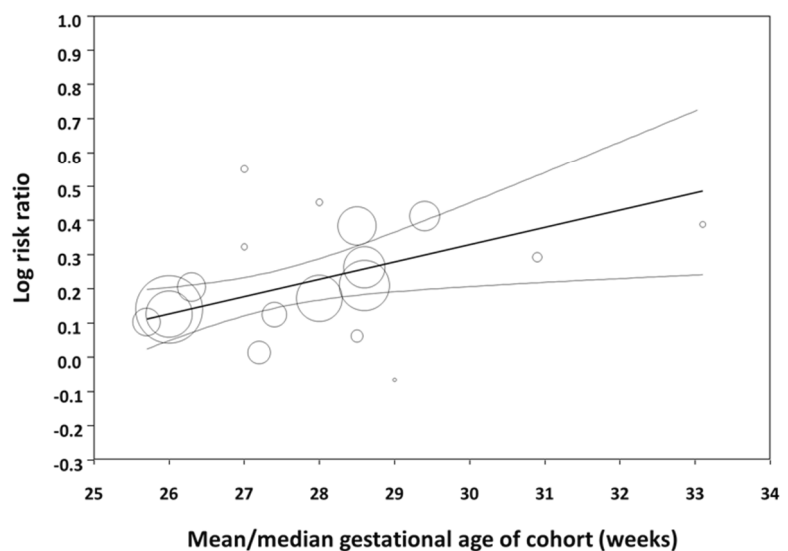

Figure 3. Meta-regression. (A) Plot showing the correlation between the association of male sex with mortality in preterm infants and the median year of birth of each cohort. A total of 24 studies were included (coefficient, -0.009 ; standard error, 0.004; $p=0.019 ; \mathrm{R}^{2}$-analog, 0.37). (B) Plot showing the correlation between the association of male sex with mortality in preterm infants and mean $/$ median gestational age of each cohort. A total of 18 studies were included (coefficient, 0.051; standard error, $0.014 ; p<0.001 ; R^{2}$-analog, 0.75). 


\section{Discussion}

To the best of our knowledge, this is the first systematic review and meta-analysis focused on male-female differences in short-term outcomes of prematurity. Our results confirm the presence of male disadvantage in mortality as well as relevant morbidities, including IVH, BPD, ROP, and NEC. Although the observed increases in risk are modest, they hold important implications for understanding preterm birth complications. Besides the short-term complications, we investigated whether other prognostic factors such as GA, birth weight, obstetric history, or clinical condition in the first days of life were different between boys and girls. We found no male-female differences in GA but the well-known difference is birth weight. In addition, meta-analysis showed that male sex was associated with decreased risk of being exposed to hypertension during pregnancy, developing fetal distress, and being born by cesarean section but increased risk of birth in a non-tertiary hospital, low Apgar score, intubation at birth, developing respiratory distress, being treated with surfactant and mechanical ventilation, developing pneumothorax, receiving postnatal steroids, and developing late onset sepsis. These differences in clinical course may have a major influence on the development of the pulmonary, neurological, ocular, and gastrointestinal complications of prematurity. On the other hand, our meta-analysis could not demonstrate that the rates of hypotension, PDA, or early onset sepsis were significantly different between boys and girls.

Male-female differences in human health and disease have been recognized for many years [54-57]. In reproductive and perinatal medicine, there are numerous studies dealing with sex differences, extending from fertilization and embryo implantation to the neonatal period [58-66]. The male to female ratio at birth is generally estimated to be around 1.05-1.06 [63-65,67]. This excess of males at birth is known for centuries and has been extensively studied by demographers, statisticians, epidemiologists, and biologists [63]. Focusing exclusively on preterm birth, the excess of males is even higher with male to female ratios around $1.2[63-65,68,69]$. However, the underlying mechanisms for this difference remain unclear, with suggestions including sexual dimorphism in embryonic and fetal homeostasis, as well as in the pathophysiological pathways that trigger preterm birth.

Preterm birth is always the result of a pathologic process, which may not only contribute to early delivery but may also adversely affect neonatal outcomes [16,70-73] The pathophysiological pathways, or endotypes, leading to very and extreme preterm birth are divided into two main groups: (1) intrauterine infection/inflammation, and (2) dysfunctional placentation [16,70-73]. The first group is related to chorioamnionitis and placental microbial invasion and is associated with preterm labor, pre-labor premature rupture of membranes, placental abruption, and cervical insufficiency. The second group is associated with hypertensive disorders of pregnancy (including preeclampsia, eclampsia, and pregnancy-induced hypertension), and the entity identified as fetal indication/IUGR [16,70-73]. The association between fetal sex and prematurity endotype has been particularly examined in the case of the dysfunctional placentation endotype. A number of meta-analysis showed that preterm preeclampsia is associated with carrying a female fetus, while pregnancies with a male fetus are associated with developing term and post-term preeclampsia [61,62]. Accordingly, we observed an increased risk of hypertensive disorders of pregnancy and fetal distress associated with female sex. In contrast, there was no evidence of sexual dimorphism for conditions related to the infectious-inflammatory endotype, such as chorioamnionitis or rupture of membranes. Nevertheless, it should be taken into account that the low number of studies reporting on these prenatal conditions limits the power of the meta-analysis to detect possible differences. In fact, it has been suggested that pregnancy with a male fetus may favor a more pro-inflammatory intra-uterine environment, leading to a higher incidence of infection/inflammation-driven preterm birth $[59,69,74]$. Our group is currently conducting a meta-analysis exclusively focused on the association between fetal sex and endotype of prematurity.

Regardless of the imbalanced sex ratio at birth, the underlying mechanisms specifically responsible for the observed increase in neonatal morbidity in preterm boys are likely 
multifactorial and not yet fully elucidated. Possible explanations include male-female differences in mother-fetus interaction, rate of fetal development, molecular differences between sex chromosomes, epimutations that preferentially affect one sex, variations in antioxidant capacity, and hormonal differences $[7,11,58-60,64-66]$. Since the dawn of neonatology, the degree of pulmonary maturity at birth has been recognized as the critical factor in determining the survival and prognosis of preterm infants [75]. It was also noted early on that preterm boys had a higher rate and severity of respiratory distress syndrome than preterm girls [76]. This has been linked to the influence of sex hormones on lung development and maturation and to anatomic differences in lung development during fetal life $[57,77,78]$. As reviewed by Seaborn et al., the lung of male fetuses is exposed to higher levels of testosterone in the period preceding the surge of surfactant production $[77,78]$. Thereafter, both sexes are exposed to increasing levels of estradiol but the fetal lung has the capability to synthesize and inactivate sex hormones, and hence to modulate their action in a sex-dependent way [78]. The present meta-analysis confirms that the respiratory clinical course is less favorable in preterm boys than in preterm girls. As mentioned above, these differences in the first days of life may be critical for the later development of other complications of prematurity.

As mentioned in the introduction, oxidative stress plays a central pathogenic role in the development of most of the complications of prematurity $[9,79,80]$. Thus, sex differences in the development of antioxidant defenses are frequently pointed out as the key factor for male disadvantage among preterm infants [10-12]. From this perspective, the glutathione pathway is the most extensively studied [10-12]. Glutathione is the major endogenous soluble antioxidant in mammalian cells and its metabolism controls the intracellular levels of peroxides (via glutathione peroxidase), aldehydes (via glutathione S-transferase), and even radicals (via regeneration of oxidized vitamins $C$ and E) [12]. As reviewed by Lavoie and Tremblay, numerous factors related to glutathione metabolism, including glutathione levels, activity of enzymes (glutathione peroxidase, glutathione reductase, glutathione S-transferase), and cellular uptake of cysteine have been found as sex-dependent in the placenta, umbilical cord, and blood cells of preterm infants [12]. Therefore, it has been suggested that antioxidant strategies in preterm infants should mainly target glutathione metabolism and be personalized considering, among others, the sex specificity [12].

The study cohorts included in our meta-analysis spanned a 30-year period (1986-2016) and some of the factors affecting outcome in the early 1990s may not be so relevant to current preterm populations. Moreover, it has been suggested that the advances in perinatal medicine, which have led to a decline in mortality and improved short-term outcomes for the most vulnerable preterm infants, have had a greater impact on boys than on girls [14]. Therefore, the male disadvantage of prematurity might be decreasing over the years [14]. We have tested this hypothesis by meta-regression and found that the male disadvantage in mortality among preterm infants tends to decrease as the cohorts include infants born in recent years. However, the increased risk of developing BPD, ROP, or NEC in males did not show this decreasing trend over the years. We also used meta-regression to analyze whether male disadvantage correlated with the gestational age of the cohort. Again, this meta-regression was only significant for mortality (Figure 3B). The association between male sex and risk of mortality decreased as the cohort had a lower mean gestational age. This effect of gestational age was not observed for any of the other complications of prematurity.

The major strength of our meta-analysis is the comprehensive database search to identify all the potential studies. Thus, the 41 included studies encompassed a total population of 625,680 infants from 16 different countries, providing a significant international representation. When we performed subgroup analyses based on continent, the only outcome where we found a significant geographic difference in sex ratio was PVL. It should be noted that, in contrast to the other outcomes analyzed, PVL was the only main complication of prematurity for which the meta-analysis did not show an increased risk associated with male sex. Subgroup analysis showed that the absence of male disadvantage for PVL was 
due to the marked differences between the American and the Asian and European cohorts (Table S2). Nevertheless, this finding may be an artifact due to the limited number of studies and therefore needs to be investigated in meta-analyses specifically focused on PVL. For all other outcomes, including IVH, BPD, ROP, NEC, and mortality, sub-group analysis did not show geographic differences, suggesting that the male disadvantage of prematurity is a ubiquitous phenomenon.

The main limitation of our systematic review is that studies were included only if sex was the independent variable and the association between sex and outcome was reported for more than one complication of prematurity. Although this design allowed for comparing the impact of male disadvantage on the different outcomes, we excluded a large number of studies in which an individual outcome was the independent variable and sex, among other potential risk factors, was the dependent variable. Our group is now analyzing these studies separately. The results of these meta-analyses, which for outcomes such as ROP or BPD include more than 250 studies, will confirm the present findings and analyze more comprehensively the influence of factors such as changes in trends over the years or geographic location on male disadvantage.

\section{Conclusions}

The present data suggest that the clinical course of preterm males is more complicated than that of females from the earliest moments of life. This higher clinical instability in males seems particularly to affect the respiratory system and leads to higher mortality and short-term morbidity. Complications such as BPD, ROP, NEC, IVH, or PVL will have a serious impact on post-discharge growth and neurodevelopment, extending the male disadvantage to the years of childhood and adolescence. In numerous studies on health conditions and neurocognitive outcomes of former preterm infants, adult females frequently perform better than adult males $[1,7,81-83]$. An improved understanding of sex-specific requirements of preterm infants may lead to optimized strategies to avoid the sequelae of early life oxidative stress and inflammation [7].

Supplementary Materials: The following are available online at https:/ /www.mdpi.com/article/10 .3390/antiox10091490/s1, Table S1: Search strategy; Table S2: Characteristics of the included studies; Table S3: Subgroup analyses based on continent; Table S4: Meta-regression analysis (continuous covariates); Figure S1: Flow diagram of the systematic search; Figure S2: Meta-analysis of the association between male sex of preterm infants and risk of bronchopulmonary dysplasia (BPD), defined as oxygen requirement on postnatal day 28; Figure S3: Meta-analysis of the association between male sex of preterm infants and risk of bronchopulmonary dysplasia (BPD), defined as oxygen requirement at the postmenstrual age of 36 weeks; Figure S4: Meta-analysis of the association between male sex and risk of intraventricular hemorrhage (IVH, grade 1-4) in preterm infants; Figure S5: Meta-analysis of the association between male sex and risk of severe intraventricular hemorrhage (IVH grade 3-4) in preterm infants; Figure S6: Meta-analysis of the association between male sex and risk of periventricular leukomalacia (PVL) in preterm infants; Figure S7: Meta-analysis of the association between male sex of preterm infants and risk of severe intraventricular hemorrhage (IVH grade 3-4) or periventricular leukomalacia (PVL); Figure S8: Meta-analysis of the association between male sex of preterm infants and risk of retinopathy of prematurity (ROP, any stage); Figure S9: Meta-analysis of the association between male sex in preterm infants and risk of severe retinopathy of prematurity (ROP grade $\geq 3$ or requiring treatment); Figure S10: Meta-analysis of the association between male sex and risk of necrotizing enterocolitis (NEC, any stage) in preterm infants; Figure S11: Meta-analysis of the association between male sex and risk of necrotizing enterocolitis (NEC, stage $\geq$ II) in preterm infants; Figure S12: Meta-analysis of the association between male sex and risk of mortality before discharge in preterm infants; Figure S13: Funnel plot for publication bias analysis for the studies included in the different meta-analyses.

Author Contributions: Conceptualization, E.V. and E.V.-M.; methodology, E.V. and E.V.-M.; validation, E.v.W.-K., M.J.H..; formal analysis, E.V., E.v.W.-K., M.J.H. and E.V.-M.; investigation, E.V., E.v.W.-K., M.J.H. and E.V.-M.; data curation, E.V., E.v.W.-K., M.J.H. and E.V.-M.; writing—original 
draft preparation, E.V.; writing-review and editing, E.V., E.v.W.-K., M.J.H. and E.V.-M; visualization, E.V.; supervision, E.V. All authors have read and agreed to the published version of the manuscript.

Funding: This research received no external funding.

Institutional Review Board Statement: As this systematic review and meta-analysis did not involve animal subjects or personally identifiable information on human subjects, ethics review board approval and patient consent were not required.

Informed Consent Statement: Not applicable.

Data Availability Statement: All data relevant to the study are included in the article or uploaded as supplementary information. Additional data are available upon reasonable request.

Acknowledgments: We thank Zozaya for providing additional data from his study.

Conflicts of Interest: The authors declare no conflict of interest. The views expressed in this paper are those of the authors and do not necessarily reflect the policies of Statistics Netherlands.

\section{References}

1. Raju, T.N.; Buist, A.S.; Blaisdell, C.J.; Moxey-Mims, M.; Saigal, S. Adults born preterm: A review of general health and systemspecific outcomes. Acta Paediatr. 2017, 106, 1409-1437. [CrossRef] [PubMed]

2. Ito, M.; Tamura, M.; Namba, F.; Neonatal Research Network of Japan. Role of sex in morbidity and mortality of very premature neonates. Pediatr. Int. 2017, 59, 898-905. [CrossRef]

3. Boghossian, N.S.; Geraci, M.; Edwards, E.M.; Horbar, J.D. Sex differences in mortality and morbidity of infants born at less than 30 weeks' gestation. Pediatrics 2018, 142, e20182352. [CrossRef] [PubMed]

4. Shim, S.-Y.; Cho, S.J.; Kong, K.A.; Park, E.A. Gestational age-specific sex difference in mortality and morbidities of preterm infants: A nationwide study. Sci. Rep. 2017, 7, 6161. [CrossRef]

5. Mohamed, M.A.; Aly, H. Male gender is associated with intraventricular hemorrhage. Pediatrics 2010, 125, e333-e339. [CrossRef] [PubMed]

6. O’Driscoll, D.N.; McGovern, M.; Greene, C.M.; Molloy, E.J. Gender disparities in preterm neonatal outcomes. Acta Paediatr. 2018, 107, 1494-1499. [CrossRef]

7. McDonald, F.B.; Dempsey, E.M.; O'Halloran, K.D. Caffeine therapy for apnoea of prematurity: Wake up to the fact that sex matters. Exp. Physiol. 2018, 103, 1294-1295. [CrossRef]

8. Saugstad, O.D. Hypoxanthine as an indicator of hypoxia: Its role in health and disease through free radical production. Pediatr Res. 1988, 23, 143-150. [CrossRef]

9. Perez, M.; Robbins, M.E.; Revhaug, C.; Saugstad, O.D. Oxygen radical disease in the newborn, revisited: Oxidative stress and disease in the newborn period. Free Rad. Biol. Med. 2019, 142, 61-72. [CrossRef]

10. Vento, M.; Aguar, M.; Escobar, J.; Arduini, A.; Escrig, R.; Brugada, M.; Izquierdo, I.; Asensi, M.A.; Sastre, J.; Saenz, P. Antenatal steroids and antioxidant enzyme activity in preterm infants: Influence of gender and timing. Antioxid. Redox Signal. 2009, 11, 2945-2955. [CrossRef]

11. Lorente-Pozo, S.; Parra-Llorca, A.; Torres, B.; Torres-Cuevas, I.; Nuñez-Ramiro, A.; Cernada, M.; García-Robles, A.; Vento, M. Influence of sex on gestational complications, fetal-to-neonatal transition, and postnatal adaptation. Front. Pediatr. 2018, 6, 63. [CrossRef] [PubMed]

12. Lavoie, J.-C.; Tremblay, A. Sex-specificity of oxidative stress in newborns leading to a personalized antioxidant nutritive strategy. Antioxidants 2018, 7, 49. [CrossRef]

13. Vu, H.D.; Dickinson, C.; Kandasamy, Y. Sex difference in mortality for premature and low birth weight neonates: A systematic review. Am. J. Perinatol. 2018, 35, 707-715. [PubMed]

14. Garfinkle, J.; Yoon, E.W.; Alvaro, R.; Nwaesei, C.; Claveau, M.; Lee, S.K.; Shah, P.S. Trends in sex-specific differences in outcomes in extreme preterms: Progress or natural barriers? Arch. Dis. Child. Fetal Neonatal Ed. 2020, 105, 158-163. [CrossRef] [PubMed]

15. Stroup, D.F.; Berlin, J.A.; Morton, S.C.; Olkin, I.; Williamson, G.D.; Rennie, D.; Moher, D.; Becker, B.J.; Sipe, T.A.; Thacker, S.B. Meta-analysis of observational studies in epidemiology: A proposal for reporting. JAMA 2000, 283, 2008-2012. [CrossRef]

16. Wells, G.A.; Shea, B.; O'Connell, D.; Peterson, J.; Welch, V.; Losos, M.; Tugwell, P. The Newcastle-Ottawa Scale (NOS) for Assessing the Quality of Nonrandomised Studies in Meta-Analyses. Oxford. 2000. Available online: http://www.ohri.ca/programs/ clinical_epidemiology / oxford.asp (accessed on 1 July 2020).

17. Pierro, M.; Villamor-Martinez, E.; van Westering-Kroon, E.; Alvarez-Fuente, M.; Abman, S.H.; Villamor, E. Association of the dysfunctional placentation endotype of prematurity with bronchopulmonary dysplasia: A systematic review, meta-analysis and meta-regression. Thorax 2021. [CrossRef]

18. Villamor-Martinez, E.; Álvarez-Fuente, M.; Ghazi, A.M.; Degraeuwe, P.; Zimmermann, L.J.; Kramer, B.W.; Villamor, E. Association of chorioamnionitis with bronchopulmonary dysplasia among preterm infants: A systematic review, meta-analysis, and metaregression. JAMA Netw. Open 2019, 2, e1914611. [CrossRef] 
19. Bertino, E.; Coscia, A.; Boni, L.; Rossi, C.; Martano, C.; Giuliani, F.; Fabris, C.; Spada, E.; Zolin, A.; Milani, S. Weight growth velocity of very low birth weight infants: Role of gender, gestational age and major morbidities. Early Hum. Dev. 2009, 85, 339-347. [CrossRef]

20. Binet, M.-E.; Bujold, E.; Lefebvre, F.; Tremblay, Y.; Piedboeuf, B.; Canadian Neonatal Network. Role of gender in morbidity and mortality of extremely premature neonates. Am. J. Perinatol. 2012, 29, 159-166. [CrossRef]

21. Chen, C.; Tian, T.; Liu, L.; Zhang, J.; Fu, H. Gender-related efficacy of pulmonary surfactant in infants with respiratory distress syndrome: A STROBE compliant study. Medicine 2018, 97, e0425. [CrossRef]

22. Derzbach, L.; Treszl, A.; Balogh, Á.; Vásárhelyi, B.; Tulassay, T. Gender dependent association between perinatal morbidity and estrogen receptor-alpha Pvull polymorphism. J. Perinat. Med. 2005, 33, 461-462. [CrossRef] [PubMed]

23. Deulofeut, R.; Dudell, G.; Sola, A. Treatment-by-gender effect when aiming to avoid hyperoxia in preterm infants in the NICU. Acta Paediatr. 2007, 96, 990-994. [CrossRef] [PubMed]

24. Elsmén, E.; Pupp, I.H.; Hellström-Westas, L. Preterm male infants need more initial respiratory and circulatory support than female infants. Acta Paediatr. 2004, 93, 529-533. [CrossRef] [PubMed]

25. Gagliardi, L.; Rusconi, F.; Reichman, B.; Adams, M.; Modi, N.; Lehtonen, L.; Kusuda, S.; Vento, M.; Darlow, B.A.; Bassler, D. Neonatal outcomes of extremely preterm twins by sex pairing: An international cohort study. Arch. Dis. Child. Fetal Neonatal Ed. 2021, 106, 17-24. [CrossRef]

26. Griesmaier, E.; Santuari, E.; Edlinger, M.; Neubauer, V.; Waltner-Romen, M.; Kiechl-Kohlendorfer, U. Differences in the maturation of amplitude-integrated EEG signals in male and female preterm infants. Neonatology 2014, 105, 175-181. [CrossRef]

27. Harris, C.; Zivanovic, S.; Lunt, A.; Calvert, S.; Bisquera, A.; Marlow, N.; Peacock, J.L.; Greenough, A. Lung function and respiratory outcomes in teenage boys and girls born very prematurely. Pediatr. Pulmonol. 2020, 55, 682-689. [CrossRef]

28. Hintz, S.R.; Kendrick, D.E.; Vohr, B.R.; Poole, W.K.; Higgins, R.D.; NICHD Neonatal Research Network. Gender differences in neurodevelopmental outcomes among extremely preterm, extremely-low-birthweight infants. Acta Paediatr. 2006, 95, 1239-1248. [CrossRef] [PubMed]

29. Huang, H.-M.; Lin, S.-A.; Chang, Y.-C.; Kuo, H.-K. Correlation between periventricular leukomalacia and retinopathy of prematurity. Eur. J. Ophthalmol. 2012, 22, 980-984. [CrossRef]

30. Jennische, M.; Sedin, G. Gender differences in outcome after neonatal intensive care: Speech and language skills are less influenced in boys than in girls at 6.5 years. Acta Paediatr. 2003, 92, 364-378. [CrossRef]

31. Jones, H.P.; Karuri, S.; Cronin, C.M.; Ohlsson, A.; Peliowski, A.; Synnes, A.; Lee, S.K. Actuarial survival of a large Canadian cohort of preterm infants. BMC Pediatr. 2005, 5, 40. [CrossRef]

32. Kent, A.L.; Wright, I.M.; Abdel-Latif, M.E. Mortality and adverse neurologic outcomes are greater in preterm male infants. Pediatrics 2012, 129, 124-131. [CrossRef]

33. Lauterbach, M.D.; Raz, S.; Sander, C.J. Neonatal hypoxic risk in preterm birth infants: The influence of sex and severity of respiratory distress on cognitive recovery. Neuropsychology 2001, 15, 411. [CrossRef] [PubMed]

34. Lavoie, M.E.; Robaey, P.; Stauder, J.E.; Glorieux, J.; Lefebvre, F. Extreme prematurity in healthy 5-year-old children: A re-analysis of sex effects on event-related brain activity. Psychophysiology 1998, 35, 679-689. [CrossRef] [PubMed]

35. Månsson, J.; Fellman, V.; Stjernqvist, K.; EXPRESS Study Group. Extremely preterm birth affects boys more and socio-economic and neonatal variables pose sex-specific risks. Acta Paediatr. 2015, 104, 514-521. [CrossRef] [PubMed]

36. Melamed, N.; Yogev, Y.; Glezerman, M. Effect of fetal sex on pregnancy outcome in twin pregnancies. Obs. Gynecol. 2009, 114, 1085-1092. [CrossRef] [PubMed]

37. Neubauer, V.; Griesmaier, E.; Ralser, E.; Kiechl-Kohlendorfer, U. The effect of sex on outcome of preterm infants-A populationbased survey. Acta Paediatr. 2012, 101, 906-911. [CrossRef]

38. Peacock, J.L.; Marston, L.; Marlow, N.; Calvert, S.A.; Greenough, A. Neonatal and infant outcome in boys and girls born very prematurely. Pediatr. Res. 2012, 71, 305-310. [CrossRef]

39. Ramos-Navarro, C.; Sánchez-Luna, M.; Zeballos-Sarrato, S.; Pescador-Chamorro, I. Antenatal corticosteroids and the influence of sex on morbidity and mortality of preterm infants. J. Matern. Fetal Neonatal Med. 2020, 1-8. [CrossRef]

40. Shinwell, E.S.; Reichman, B.; Lerner-Geva, L.; Boyko, V.; Blickstein, I. "Masculinizing" effect on respiratory morbidity in girls from unlike-sex preterm twins: A possible transchorionic paracrine effect. Pediatrics 2007, 120, e447-e453. [CrossRef]

41. Skiöld, B.; Alexandrou, G.; Padilla, N.; Blennow, M.; Vollmer, B.; Ådén, U. Sex differences in outcome and associations with neonatal brain morphology in extremely preterm children. J. Pediatr. 2014, 164, 1012-1018. [CrossRef]

42. Spinillo, A.; Montanari, L.; Gardella, B.; Roccio, M.; Stronati, M.; Fazzi, E. Infant sex, obstetric risk factors, and 2-year neurodevelopmental outcome among preterm infants. Dev. Med. Child Neurol. 2009, 51, 518-525. [CrossRef] [PubMed]

43. Stark, M.J.; Hodyl, N.A.; Wright, I.M.; Clifton, V. The influence of sex and antenatal betamethasone exposure on vasoconstrictors and the preterm microvasculature. J. Matern. Fetal Neonatal Med. 2011, 24, 1215-1220. [CrossRef] [PubMed]

44. Stark, M.J.; Wright, I.M.; Clifton, V.L. Sex-specific alterations in placental $11 \beta$-hydroxysteroid dehydrogenase 2 activity and early postnatal clinical course following antenatal betamethasone. Am. J. Physiol. Regul. Integrat. Compar. Physiol. 2009, 297, R510-R514. [CrossRef] [PubMed]

45. Steen, E.E.; Källén, K.; Maršál, K.; Norman, M.; Hellström-Westas, L. Impact of sex on perinatal mortality and morbidity in twins. J. Perinat. Med. 2014, 42, 225-231. [CrossRef] [PubMed] 
46. Stevenson, D.K.; Verter, J.; Fanaroff, A.A.; Oh, W.; Ehrenkranz, R.A.; Shankaran, S.; Donovan, E.F.; Wright, L.L.; Lemons, J.A.; Tyson, J.E. Sex differences in outcomes of very low birthweight infants: The newborn male disadvantage. Arch. Dis. Child. Fetal Neonatal Ed. 2000, 83, F182-F185. [CrossRef] [PubMed]

47. Štimac, T.; Šopić-Rahelić, A.-M.; Ivandić, J.; Ekinja, E.; Blickstein, I. Effect of gender on growth-restricted fetuses born preterm. J. Perinat. Med. 2019, 47, 677-679. [CrossRef]

48. Tioseco, J.A.; Aly, H.; Essers, J.; Patel, K.; El-Mohandes, A.A. Male sex and intraventricular hemorrhage. Pediatr. Crit. Care Med. 2006, 7, 40-44. [CrossRef]

49. Tottman, A.C.; Bloomfield, F.H.; Cormack, B.E.; Harding, J.E.; Taylor, J.; Alsweiler, J.M. Sex-specific relationships between early nutrition and neurodevelopment in preterm infants. Pediatr. Res. 2020, 87, 872-878. [CrossRef]

50. Walker, M.; Fitzgerald, B.; Keating, S.; Ray, J.; Windrim, R.; Kingdom, J. Sex-specific basis of severe placental dysfunction leading to extreme preterm delivery. Placenta 2012, 33, 568-571. [CrossRef] [PubMed]

51. Wang, L.-W.; Lin, Y.-C.; Wang, S.-T.; Huang, C.-C.; Taiwan Premature Infant Developmental Collaborative Study Group. Identifying risk factors shared by bronchopulmonary dysplasia, severe retinopathy, and cystic periventricular leukomalacia in very preterm infants for targeted intervention. Neonatology 2018, 114, 17-24. [CrossRef] [PubMed]

52. Zhao, D.; Zou, L.; Lei, X.; Zhang, Y. Gender differences in infant mortality and neonatal morbidity in mixed-gender twins. Sci. Rep. 2017, 7, 8736. [CrossRef] [PubMed]

53. Zisk, J.L.; Genen, L.H.; Kirkby, S.; Webb, D.; Greenspan, J.; Dysart, K. Do premature female infants really do better than their male counterparts? Am. J. Perinatol. 2011, 28, 241-246. [CrossRef]

54. Zozaya, C.; Avila-Alvarez, A.; Arruza, L.; Rodrigo, F.G.-M.; Fernandez-Perez, C.; Castro, A.; Cuesta, M.T.; Vacas, B.; Couce, M.L.; Torres, M.V. The effect of morbidity and sex on postnatal growth of very preterm infants: A multicenter cohort study. Neonatology 2019, 115, 348-354. [CrossRef]

55. Editorial. Putting gender on the agenda. Nature 2010, 465, 665. [CrossRef] [PubMed]

56. Kardys, I.; Vliegenthart, R.; Oudkerk, M.; Hofman, A.; Witteman, J.C. The female advantage in cardiovascular disease: Do vascular beds contribute equally? Am. J. Epidemiol. 2007, 166, 403-412. [CrossRef] [PubMed]

57. Van Oyen, H.; Nusselder, W.; Jagger, C.; Kolip, P.; Cambois, E.; Robine, J.-M. Gender differences in healthy life years within the EU: An exploration of the "health-survival" paradox. Int. J. Public Health 2013, 58, 143-155. [CrossRef] [PubMed]

58. Townsend, E.A.; Miller, V.M.; Prakash, Y. Sex differences and sex steroids in lung health and disease. Endocr. Rev. 2012, 33, 1-47. [CrossRef] [PubMed]

59. Gabory, A.; Roseboom, T.; Moore, T.; Moore, L.; Junien, C. Placental contribution to the origins of sexual dimorphism in health and diseases: Sex chromosomes and epigenetics. Biol. Sex Differ. 2013, 4, 5. [CrossRef] [PubMed]

60. Clifton, V. Sex and the human placenta: Mediating differential strategies of fetal growth and survival. Placenta 2010, 31, S33-S39. [CrossRef]

61. Clifton, V.; Stark, M.; Osei-Kumah, A.; Hodyl, N. The feto-placental unit, pregnancy pathology and impact on long term maternal health. Placenta 2012, 33, S37-S41. [CrossRef]

62. Broere-Brown, Z.A.; Adank, M.C.; Benschop, L.; Tielemans, M.; Muka, T.; Gonçalves, R.; Bramer, W.M.; Schoufour, J.D.; Voortman, T.; Steegers, E.A. Fetal sex and maternal pregnancy outcomes: A systematic review and meta-analysis. Biol. Sex Differ. 2020, 11, 26. [CrossRef]

63. Schalekamp-Timmermans, S.; Arends, L.R.; Alsaker, E.; Chappell, L.; Hansson, S.; Harsem, N.K.; Jälmby, M.; Jeyabalan, A.; Laivuori, H. Fetal sex-specific differences in gestational age at delivery in pre-eclampsia: A meta-analysis. Int. J. Epidemiol. 2017, $46,632-642$.

64. James, W.H.; Grech, V. A review of the established and suspected causes of variations in human sex ratio at birth. Early Hum. Dev. 2017, 109, 50-56. [CrossRef]

65. Ingemarsson, I. Gender aspects of preterm birth. BJOG Int. J. Obs. Gynaecol. 2003, 110, 34-38. [CrossRef]

66. Cooperstock, M.; Campbell, J. Excess males in preterm birth: Interactions with gestational age, race, and multiple birth. Obs. Gynecol. 1996, 88, 189-193. [CrossRef]

67. DiPietro, J.A.; Voegtline, K.M. The gestational foundation of sex differences in development and vulnerability. Neuroscience 2017, 342, 4-20. [CrossRef] [PubMed]

68. Martin, J.A.; Hamilton, B.E.; Osterman, M.J.; Driscoll, A.K. Births: Final data for 2019. Natl. Vital Stat. Rep. $2021,70,1-51$.

69. Peelen, M.J.; Kazemier, B.M.; Ravelli, A.C.; De Groot, C.J.; Van Der Post, J.A.; Mol, B.W.; Hajenius, P.J.; Kok, M. Impact of fetal gender on the risk of preterm birth, a national cohort study. Acta Obs. Gynecol. Scand. 2016, 95, 1034-1041. [CrossRef]

70. Challis, J.; Newnham, J.; Petraglia, F.; Yeganegi, M.; Bocking, A. Fetal sex and preterm birth. Placenta 2013, 34, 95-99. [CrossRef] [PubMed]

71. McElrath, T.F.; Hecht, J.L.; Dammann, O.; Boggess, K.; Onderdonk, A.; Markenson, G.; Harper, M.; Delpapa, E.; Allred, E.N.; Leviton, A. Pregnancy disorders that lead to delivery before the 28th week of gestation: An epidemiologic approach to classification. Am. J. Epidemiol. 2008, 168, 980-989. [CrossRef]

72. Gagliardi, L. Pregnancy complications and neonatal outcomes: Problems and perspectives. Acta Paediatr. 2014, 103, 682-683. [CrossRef] [PubMed] 
73. Gagliardi, L.; Rusconi, F.; Da Fre, M.; Mello, G.; Carnielli, V.; Di Lallo, D.; Macagno, F.; Miniaci, S.; Corchia, C.; Cuttini, M. Pregnancy disorders leading to very preterm birth influence neonatal outcomes: Results of the population-based ACTION cohort study. Pediatr. Res. 2013, 73, 794-801. [CrossRef]

74. Gagliardi, L.; Rusconi, F.; Bellu, R.; Zanini, R.; Italian Neonatal Network. Association of maternal hypertension and chorioamnionitis with preterm outcomes. Pediatrics 2014, 134, e154-e161. [CrossRef]

75. Ghidini, A.; Salafia, C.M. Histologic placental lesions in women with recurrent preterm delivery. Acta Obs. Gynecol. Scand. 2005, 84, 547-550. [CrossRef] [PubMed]

76. Cataltepe, D. Historical perspectives: Beyond the first breath: Hyaline membrane disease and constructing the neonatal patient, 1959-1975. NeoReviews 2018, 19, e636-e644. [CrossRef]

77. Farrell, P.M.; Avery, M.E. Hyaline membrane disease. Am. Rev. Respir. Dis. 1975, 111, 657-688. [PubMed]

78. Raghavan, D.; Jain, R. Increasing awareness of sex differences in airway diseases. Respirology 2016, 21, 449-459. [CrossRef] [PubMed]

79. Seaborn, T.; Simard, M.; Provost, P.R.; Piedboeuf, B.; Tremblay, Y. Sex hormone metabolism in lung development and maturation. Trends Endocrinol. Metabol. 2010, 21, 729-738. [CrossRef]

80. Huizing, M.J.; Cavallaro, G.; Moonen, R.M.; González-Luis, G.E.; Mosca, F.; Vento, M.; Villamor, E. Is the C242T polymorphism of the CYBA gene linked with oxidative stress-associated complications of prematurity? Antioxid. Redox Signal. 2017, 27, 1432-1438. [CrossRef]

81. Linsell, L.; Malouf, R.; Morris, J.; Kurinczuk, J.J.; Marlow, N. Prognostic factors for poor cognitive development in children born very preterm or with very low birth weight: A systematic review. JAMA Pediatr. 2015, 169, 1162-1172. [CrossRef]

82. Linsell, L.; Johnson, S.; Wolke, D.; O’Reilly, H.; Morris, J.K.; Kurinczuk, J.J.; Marlow, N. Cognitive trajectories from infancy to early adulthood following birth before 26 weeks of gestation: A prospective, population-based cohort study. Arch. Dis. Child. 2018, 103, 363-370. [CrossRef] [PubMed]

83. Darlow, B.A.; Martin, J.; Horwood, L.J. Metabolic syndrome in very low birth weight young adults and controls: The New Zealand 1986 VLBW Study. J. Pediatr. 2019, 206, 128-133.e5. [CrossRef] [PubMed] 